\title{
A comparative study of astigmatism following manual small incision cataract surgery and conventional extracapsular cataract extraction at a tertiary centre in Northern India
}

\author{
Khanday $\mathbf{S}^{1}$, Wani $\mathbf{R M}^{2}$, Ramzan $\mathbf{R}^{3}$, Runyal $\mathbf{F}^{4}$ \\ ${ }^{1}$ Dr Sajad Khanday, Assistant Professor, Department of Ophthalmology, GMC Srinagar, ${ }^{2}$ Dr Raashid Maqbool Wani, \\ Senior Resident, Dept of Ophthalmology, GMC Srinagar, ${ }^{3}$ Dr Rahila Ramzan, Senior Resident, Dept of Ophthalmology \\ GMC Srinagar, ${ }^{4}$ Dr Farooq Runyal, Post graduate student, Department of Ophthalmology, GMC Srinagar, Jammu \& \\ Kashmir, India.
}

Address for correspondence: Dr Raashid Maqbool Wani, Email: raashid.maqboolwani@gmail.com

\begin{abstract}
Objective: To compare the surgically induced astigmatism following two different techniques of cataract surgerymanual SICS (Small Incision Cataract Surgery) and standard ECCE (Extra-Capsular Cataract Extraction). Materials and Methods: Subjects consisted of patients, aged 10-80 years, from both sexes and divided into two groups of 100 each (one eye per patient). One group was operated with manual SICS and the other with standard ECCE technique. Results: The mean surgically induced astigmatism (SIA) in the SICS group during the sixth week postoperative follow up was found to be $0.66 \mathrm{D} \pm 0.60 \mathrm{SD}$ (Standard Deviation) compared to $2.25 \mathrm{D} \pm 1.23 \mathrm{SD}$ in the ECCE group. At $6^{\text {th }}$ week follow up, no patient in the SICS group had SIA more than 3D whereas in the ECCE group $30 \%$ of the patients had astigmatism $>3 \mathrm{D}$. The induced astigmatism between the two groups had a p-value of $<0.001$ which is highly significant. Conclusions: It is concluded that SICS induces less surgically induced astigmatism, less inflammation, less complications influencing the overall visual prognosis and quick stabilization of refraction, hence providing better and rapid visual rehabilitation in the postoperative period as compared to the patients in the ECCE group.
\end{abstract}

Key words: SICS (Small Incision Cataract Surgery), ECCE (Extra-Capsular Cataract Extraction), Astigmatism

\section{Introduction}

Senile cataract is most important cause of reversible blindness in India and other developing countries [1]. Now-a-days, all techniques of cataract extraction are being modified to give best uncorrected visual acuity and early rehabilitation [2]. In the same race conventional Extra Capsular Cataract Extraction (ECCE) was improved to manual Small Incision Cataract Surgery (SICS) and Phacoemulsification.

The disadvantages of conventional large incision ECCE is that technically it is more difficult to make large incisions. It is exposed to increased risks of expulsive hemorrhage, difficulty in suturing while closing the section. Postoperatively large incisions are associated with more inflammation and suture induced problems such as astigmatism and irritation. Refraction remains

Manuscript received: $20^{\text {th }}$ May 2015

Reviewed: $24^{\text {th }}$ May 2015

Author Corrected: $7^{\text {th }}$ June 2015

Accepted for Publication: $16^{\text {th }}$ June 2015 changing for many months postoperatively and induced astigmatism is more, thereby resulting in delayed and unsatisfactory visual rehabilitation.

Though phacoemulsification has emerged as "state of art", in the developing countries, the cost and the maintenance factor put it beyond the availability to most patients. Thus many surgeons world over are considering "Manual small incision cataract surgerySICS", which is cost effective, safe with low postoperative inflammation, requiring fewer visits for follow up care. Due to earlier stabilization of refraction and less surgically induced astigmatism (SIA) visual rehabilitation is quick and satisfying. Furthermore astigmatically neutral incisions can be performed to counter any preexisting astigmatism, making this technique both a therapeutic and a refractive procedure.

Small incision sutureless cataract surgery permits high volume, high quality, low cost surgeries with speed and 
safety and hence holds major importance in rural centers especially in developing countries facing enormous surgical volumes and limited resources [3].

Pioneering work by Kelman predicted that incisions $3 \mathrm{~mm}$ wide would be astigmatism neutral because of their reduced size [4]. Richard Kratz is credited as the first surgeon to develop the posterior sclera incision [5]. Girrard and Hoffman were the first to call this posterior incision as the "Scleral tunnel incision" [6]. Jaffe has stated that a $7 \mathrm{~mm}$ incision $2 \mathrm{~mm}$ behind the limbus can be left unsutured without the fear of induced against the rule astigmatism. Hydroprocedures were described by Professor Michael Blumenthal but the term was coined by Faust [7]. Hydrodissection is the separation of cortex from the epinucleus by a fluid wave while as Hydrodilineation is the separation of epinucleus from endonucleus by a fluid wave.

\section{Methods}

The study was conducted in the Department of Ophthalmology, Government Medical College, Srinagar (Kashmir), during the time period $1^{\text {st }}$ January 2011 to $31^{\text {st }}$ December 2012. It was a single centre prospective comparative study. The study was undertaken in randomly selected 200 patients (200 eyes, one eye per patient) of both sexes aged 10 to 80 years, divided into two groups. 100 patients were operated using manual SICS technique and the other 100 underwent standard ECCE technique. The exclusion criteria likely to influence the visual prognosis included: Previous Intraocular Surgery, Significant Corneal Opacification, Uveitis, Glaucoma \& High Myopia.

Routine evaluation was performed in all the patients including complete personal and family history, uncorrected visual acuity (UCVA), best corrected visual acuity (BCVA), tonometry, slit lamp examination, funduscopy, keratometry (for preoperative astigmatism) \& IOL power calculation. Preoperatively antibiotics were given for three days prior to surgery. In the manual SICS group, the external incision given was 0.3 $\mathrm{mm}$ deep, 5-6 $\mathrm{mm}$ in length, $1 \mathrm{~mm}$ behind the limbus with Frown configuration. The scleral tunnel was fashioned with a crescent blade extending 1-2 mm into the clear cornea, capsulotomy was performed followed by hydro dissection and hydro delineation The lens was gently rotated and gradually dislocated into the anterior chamber and the nucleus delivered by viscoexpression. After cortical aspiration, IOL implantation was done, anterior chamber reformed, and stromal hydration done to check the valvular action of the tunnel. In the standard ECCE group a conventional 10-12mm limbal incision was followed by routine extra capsular method. Topical antibiotics and steroids were advised for six weeks postoperatively. Follow-up assessment was done at $1 \mathrm{st}, 3 \mathrm{rd}$, 6th and 12th week postoperatively with slit lamp examination, funduscopy, visual acuity, refraction \& keratometry (for assessing the postoperative astigmatism).

\section{Results}

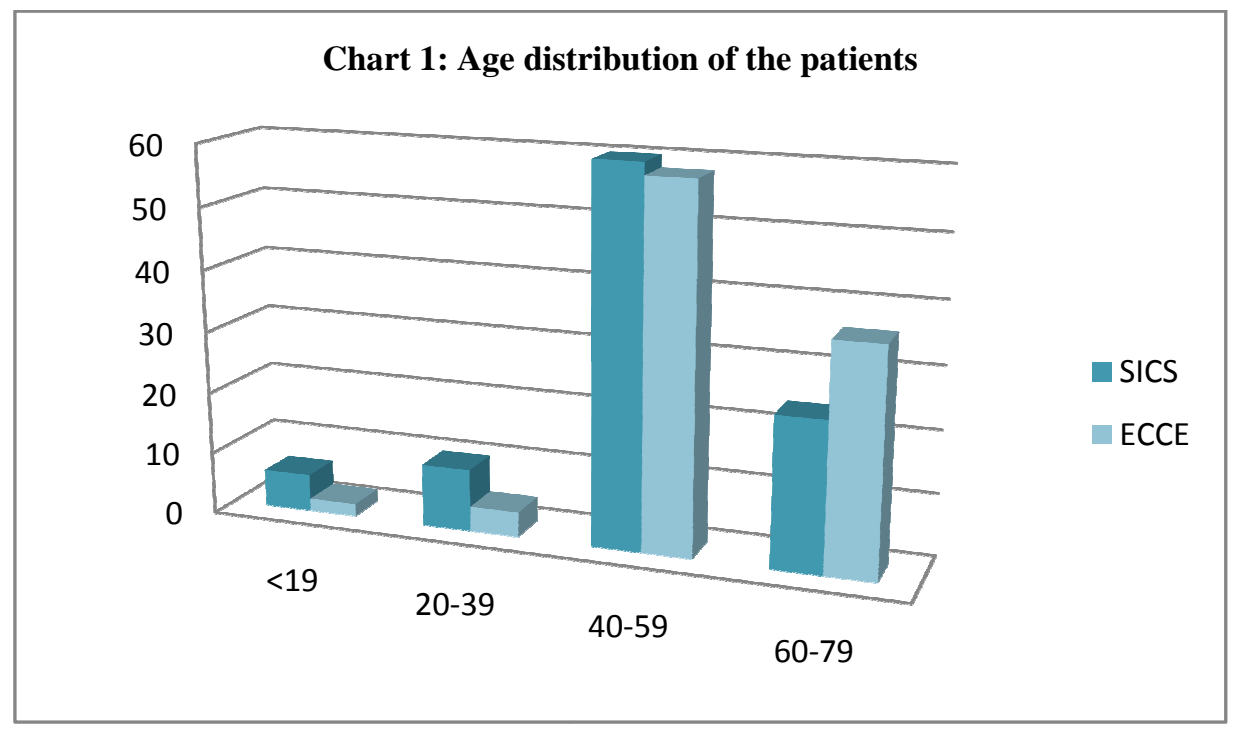

In the SICS group majority of the patients (84\%) were more than 40 years of age and in the ECCE group $94 \%$ of the patients were more than 40 years of age (Chart 1). 


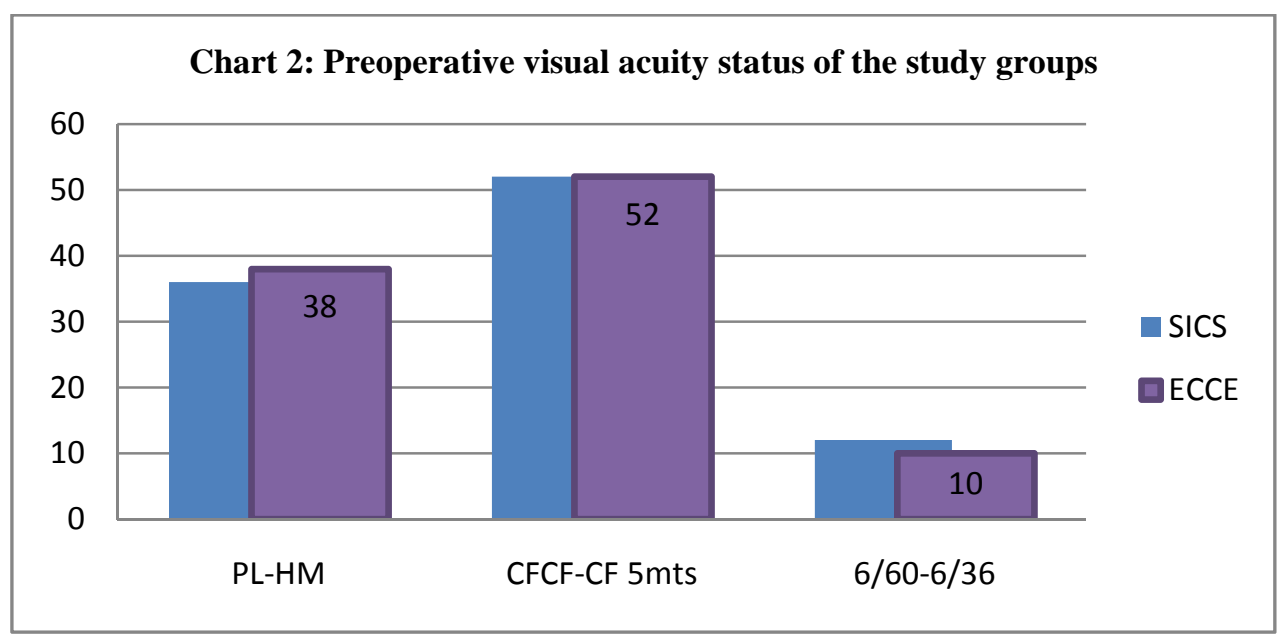

PL: Perception of light; HM: Hand Movements; CFCF: Counting finger close to face; CF: Counting Finger.

In both the groups i.e. patients undergone SICS and ECCE, 52\% patients in either of the groups had a preoperative visual acuity ranging from counting fingers close to face up to counting fingers 5 meters (Chart 2).

\begin{tabular}{|l|l|l|l|l|l|l|}
\hline TABLE-1: Preoperative Astigmatism Distribution And Pattern of Study Subjects \\
\hline \multirow{2}{*}{ Astigmatism (D) } & SICS & ECCE & Total \\
\cline { 2 - 7 } & n (100) & \% & n (100) & \% & n (200) & \% \\
\hline $\mathbf{0 . 0 0 - 1 . 0 0}$ & 92 & 92.0 & 94 & 94.0 & 186 & 93.0 \\
\hline $\mathbf{1 . 2 5 - 2 . 0 0}$ & 8 & 8.0 & 6 & 6.0 & 14 & 7.0 \\
\hline \multicolumn{7}{|l|}{} \\
\hline Type of Astigmatism & \multicolumn{7}{|l|}{} \\
\hline WTR & 78 & 78.0 & 74 & 74.0 & 152 & 76 \\
\hline ATR & 6 & 6.0 & 8 & 8.0 & 14 & 7 \\
\hline Nil & 16 & 16.0 & 18 & 18.0 & 34 & 17 \\
\hline
\end{tabular}

Majority of the patients in both the groups were having astigmatism below 1D and demonstrated a preoperative "With The Rule (WTR) Astigmatism" (Table 1).

TABLE-2: Surgically Induced Astigmatism (SIA) Distribution And Pattern at $1^{\text {st }}$ week

\begin{tabular}{|c|c|c|c|c|c|c|c|}
\hline \multirow{2}{*}{ Astigmatism(D) } & \multicolumn{2}{|l|}{ SICS } & \multicolumn{2}{|l|}{ ECCE } & \multicolumn{2}{|l|}{ Total } & \multirow{2}{*}{$P$-value } \\
\hline & n (100) & $\%$ & n (100) & $\%$ & n (200) & $\%$ & \\
\hline 0.00-1.00 & 24 & 24.0 & 0 & 0 & 24 & 12.0 & \multirow{8}{*}{$<0.001$} \\
\hline $1.25-2.00$ & 52 & 52.0 & 6 & 6.0 & 58 & 29.0 & \\
\hline $2.25-3.00$ & 18 & 18.0 & 20 & 20.0 & 38 & 19.0 & \\
\hline$>3.00$ & 6 & 6.0 & 74 & 74.0 & 80 & 40.0 & \\
\hline \multicolumn{7}{|l|}{$\begin{array}{l}\text { Type of } \\
\text { Astigmatism }\end{array}$} & \\
\hline WTR & 4 & 4.0 & 96 & 96.0 & 100 & 50.0 & \\
\hline ATR & 84 & 84.0 & 4 & 4.0 & 88 & 44.0 & \\
\hline Nil & 12 & 12.0 & 0 & 0 & 12 & 6.0 & \\
\hline
\end{tabular}

At $1^{\text {st }}$ week postoperatively, $76 \%$ in the SICS group had surgically induced astigmatism (SIA) of less than 2D whereas in the ECCE group $94 \%$ had SIA of magnitude more than 2D. The difference between the two was statistically significant (Table 2). 
TABLE-3: Surgically Induced Astigmatism (SIA) Distribution And Pattern at $3^{\text {rd }}$ week

\begin{tabular}{|c|c|c|c|c|c|c|c|}
\hline \multirow{2}{*}{ Astigmatism(D) } & \multicolumn{2}{|l|}{ SICS } & \multicolumn{2}{|l|}{ ECCE } & \multicolumn{2}{|l|}{ Total } & \multirow{2}{*}{$P$-value } \\
\hline & n (100) & $\%$ & n (100) & $\%$ & n (200) & $\%$ & \\
\hline 0.00-1.00 & 60 & 60.0 & 0 & 0 & 60 & 30.0 & \multirow{8}{*}{$<0.001$} \\
\hline $1.25-2.00$ & 34 & 34.0 & 18 & 18.0 & 52 & 26.0 & \\
\hline 2.25-3.00 & 06 & 6.0 & 26 & 26.0 & 32 & 16.0 & \\
\hline$>3.00$ & 0 & 0 & 56 & 56.0 & 56 & 28.0 & \\
\hline \multicolumn{7}{|l|}{$\begin{array}{l}\text { Type of } \\
\text { Astigmatism }\end{array}$} & \\
\hline WTR & 4 & 4.0 & 96 & 96.0 & 100 & 50.0 & \\
\hline ATR & 84 & 84.0 & 4 & 4.0 & 88 & 44.0 & \\
\hline Nil & 12 & 12.0 & 0 & 0 & 12 & 6.0 & \\
\hline
\end{tabular}

At $3^{\text {rd }}$ week postoperatively, $60 \%$ in the SICS group had SIA of less than 1D whereas in the ECCE group $82 \%$ had SIA of magnitude more than 2D. The difference between the two was statistically significant (Table 3 ).

\begin{tabular}{|c|c|c|c|c|c|c|c|}
\hline \multicolumn{8}{|c|}{ TABLE-4: Surgically Induced Astigmatism (SIA) Distribution And Pattern at ${ }^{\text {th }}$ week $^{-}$} \\
\hline \multirow{2}{*}{ Astigmatism (D) } & \multicolumn{2}{|c|}{ SICS } & \multicolumn{2}{|c|}{ ECCE } & \multicolumn{2}{|c|}{ Total } & \multirow{2}{*}{$P$-value } \\
\hline & n (100) & $\%$ & n (100) & $\%$ & n (200) & $\%$ & \\
\hline 0.00-1.00 & 82 & 82.0 & 18 & 18.0 & 100 & 50.0 & \multirow{9}{*}{$<0.001$} \\
\hline $1.25-2.00$ & 18 & 18.0 & 26 & 26.0 & 44 & 22.0 & \\
\hline 2.25-3.00 & 0 & 0 & 26 & 26.0 & 26 & 13.0 & \\
\hline$>3.00$ & 0 & 0 & 30 & 30.0 & 30 & 15.0 & \\
\hline & & & & & & & \\
\hline \multicolumn{7}{|l|}{$\begin{array}{l}\text { Type of } \\
\text { Astigmatism }\end{array}$} & \\
\hline WTR & 4 & 4.0 & 90 & 90.0 & 94 & 47.0 & \\
\hline ATR & 66 & 66.0 & 4 & 4.0 & 70 & 35.0 & \\
\hline Nil & 30 & 30.0 & 6 & 6.0 & 36 & 18.0 & \\
\hline
\end{tabular}

At $6^{\text {th }}$ week postoperatively, $56 \%$ in the ECCE group had SIA of less than 2D whereas in the SICS group no patient had SIA of magnitude more than 2D. The difference between the two was highly statistically significant (Table 4).

Table- 5: Mean surgically induced astigmatism (D) - (SIA \pm SD)

\begin{tabular}{|l|l|l|}
\hline Follow Up & SICS & ECCE \\
\hline $\mathbf{1}^{\text {st }}$ week & $1.60 \pm 0.90$ & $4.00 \pm 1.23$ \\
\hline $\mathbf{3}^{\text {rd }}$ week & $0.88 \pm 0.65$ & $3.50 \pm 1.23$ \\
\hline $\mathbf{6}^{\text {th }}$ week & $0.66 \pm 0.60$ & $2.25 \pm 1.23$ \\
\hline $\mathbf{1 2}^{\text {th }}$ week & $0.44 \pm 0.44$ & $2.00 \pm 1.21$ \\
\hline
\end{tabular}

The difference in SIA was found to be highly significant between the two techniques during all the postoperative follow up visits. The shift in the induced astigmatism was found to be "Against The Rule (ATR)" in the majority of the patients in the SICS group and WTR in majority of the patients in the ECCE group during all the follow ups. 


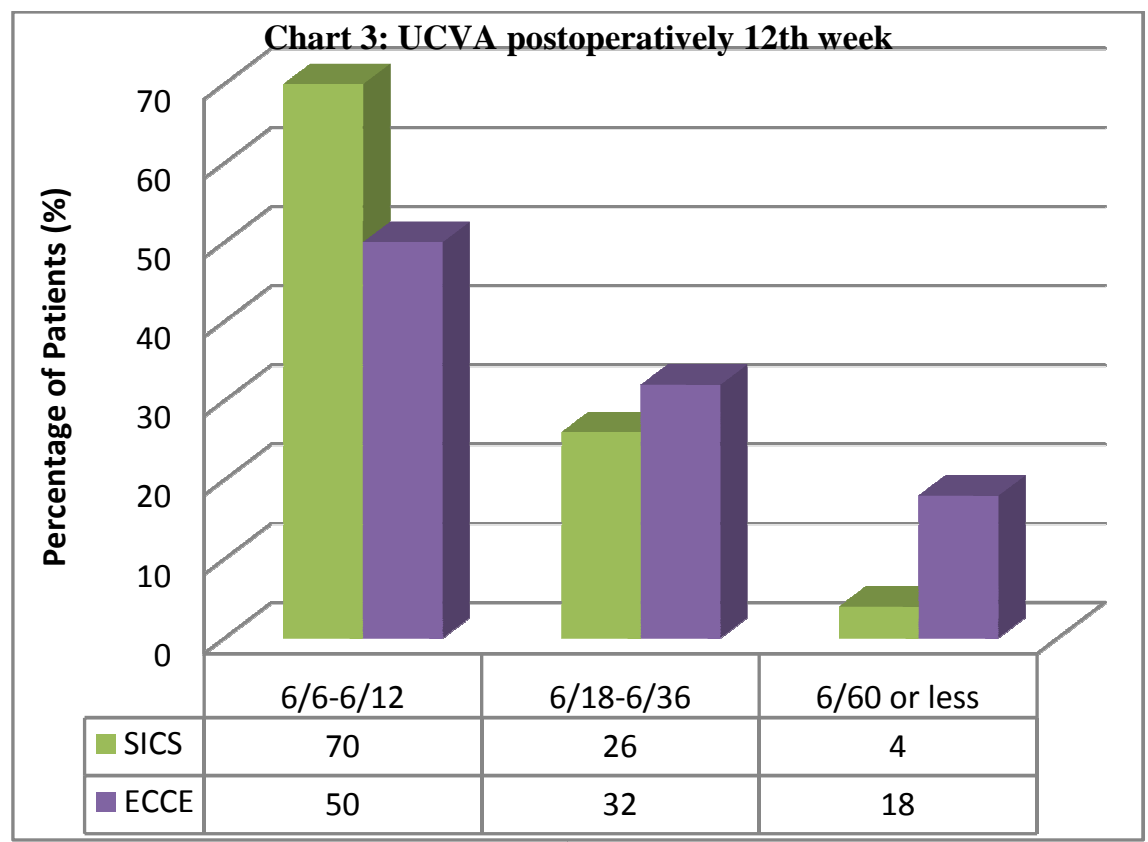

Postoperatively $12^{\text {th }}$ week, 70 patients had uncorrected visual acuity 6/6-6/12 in the SICS group whereas in ECCE group 50 patients had visual acuity in this range. Only 4 patients in the SICS group had visual acuity less than 6/60, however in the ECCE group 18 patients had visual acuity less than 6/60. The difference in the uncorrected visual acuity $12^{\text {th }}$ week postoperatively between SICS and ECCE was found to be statistically significant.

The intraoperative period was uneventful in both the techniques without any complications. Posterior chamber intraocular lens implantation was possible in all the cases. The postoperative period was also uneventful in both the groups. Four patients in the ECCE group had loose corneoscleral sutures but without any iris prolapse. Though postoperative discomfort, irritation and redness were more in the ECCE group, no significant complication was noted in either of the groups.

\section{Discussion}

It was a single centre prospective comparative study. The study was undertaken in randomly selected 200 patients (200 eyes, one eye per patient) of both sexes aged 10 to 80 years, divided into two groups. 100 patients were operated using manual SICS technique and the other 100 underwent standard ECCE technique. Majority of the patients were aged more than 40 years [Chart 1]. Most of the patients in both the groups had preoperative visual acuity status ranging from counting finger close to face to counting finger 5 meters [Chart 2]. The analysis of astigmatism was based on keratometric astigmatism as it is an objective measurement of corneal contour not influenced by lenticular astigmatism. In the SICS group $92 \%$ of the patients exhibited a preoperative astigmatism of 0-1D while as $94 \%$ of patients in the ECCE group exhibited preoperative astigmatism of $0-1 \mathrm{D}$. For assigning the astigmatism to be "with the rule (WTR)" or "against the rule (ATR)" we have employed "Algebraic Method"[8]. Based on this formula the direction of the steep axis or plus cylinder, astigmatism is divided into either:
- With The Rule WTR: $45^{\circ}<$ axis $<135^{\circ}$

- Against The Rule ATR: $135^{\circ}<$ axis $<180^{\circ}$

$$
\text { Or } 0^{\circ}<\text { axis }<45^{\circ}
$$

With these definitions if either preoperative axis ( $a_{\text {preop }}$ ) or postoperative axis $\left(b_{\text {postop }}\right.$ ) is ATR, the respective power is multiplied by -1 .

SIA $_{\text {Algebraic }}=b_{\text {postop }} \mathbf{a}_{\text {preop }}$

On the basis of the above formula, in the SICS group $78 \%$ of patients had a preoperative astigmatism of WTR, 6\% had ATR and 16\% had no preoperative astigmatism at all. In the ECCE group $74 \%$ of patients had a preoperative astigmatism of WTR, $8 \%$ had ATR and $18 \%$ had no preoperative astigmatism (Table 1).

The preoperative astigmatism is important in the final postoperative astigmatism outcome, because cornea has the tendency for natural recovery to the preoperative curvature which in interaction with SIA component affects a change in the final postoperative astigmatism status. The size and location of the incision have a profound impact on the postoperative visual results. 
Induced astigmatism is directly proportional to the cube of incision length and inversely proportional to the distance the incision is placed from the limbus [9]. Burgansky et al have shown an increase in astigmatism with an increase in incision size [10]. Kimura et al have shown by vector analysis that surgically induced astigmatism is less with an oblique incision $(1.02+0.66$ D) than with a superior incision $(1.41+0.72 \mathrm{D})$ [11]. The incision in the SICS group is $6 \mathrm{~mm}$ against the 10 $12 \mathrm{~mm}$ in the ECCE group and is about $1 \mathrm{~mm}$ away from the limbus compared to the ECCE group where the incision is just on the limbus. The results we got are quite compatible with this fundamental principle.

Scleral incisions have other advantages over clear corneal incisions like fewer chances of endophthalmitis, less glare, less wound sagging and dehiscence and irregular astigmatism [12]. Further superior approach incisions which we have employed are comparable to temporal approach in terms of visual rehabilitation and induced astigmatism [13].

Sutureless incisions when constructed properly and adequately prove to be stable incisions that resist leakage and iris prolapse at intraocular pressure of over $400 \mathrm{mmHg}$ (Hydrostatic) as these incisions are self sealing because pressure in the anterior chamber automatically pushes the lip against the intracorneal portion of the incision sealing it tightly without sutures [14]. Other advantages are absence of hyphemas and foreign body sensation from sutures, no damage to the ciliary body by suture needles and increased stability of the wound.

The mean SIA in the SICS group during the first postoperative week was found to be $1.60 \pm 0.90 \mathrm{SD}$ (Standard deviation) compared to $4.00 \pm 1.23 \mathrm{SD}$ in the ECCE group. $76 \%$ of the patients in the SICS group exhibited SIA in the range of $0-2 \mathrm{D}$ with only $6 \%$ in the ECCE group falling in this range. Using the "paired sample t-test" for determining the level of significance, p-value is $<0.001$ which is highly significant. Based on the 'algebraic method', $84 \%$ of the patients in the SICS group demonstrated ATR shift during the first week, which is explained by sutureless incisions as these tend to flatten in the meridian of the incision and steepens in the meridian $90^{\circ}$ away[Table 2]. Actually these changes are in relation to the location of the incision, so "With the wound" or "Against the wound" astigmatism is more precise and valid. Since our incision is superiorly located, so we have used WTR or ATR terms in our description for convention. These changes in the curvature are explained by the law of "elastic domes" which states that for every change in curvature in one meridian, there is an even and opposite changes $90^{\circ}$ away. $4 \%$ of the patients in the SICS group exhibited a WTR shift in SIA. This unconventional shift in sutureless surgery is explained by excessive scleral cauterization as has been explained by Troutman [15]. He proposed that thermal energy leads to cross linkage leading to uneven shrinkage of wound and difficulties even in closure.

In the ECCE group during the first postoperative week 96\% of the patients exhibited the predicted WTR shift in the SIA. This is explained by the fact that sutures cause steepening along the meridian of the incision. Too many sutures, deep bites, excessive tension applied all predispose to WTR shift and have a direct relation with the magnitude of induced astigmatism. 4\% had loose corneo-scleral sutures which caused sagging and weak apposition of the wound lips thereby causing flattening in the vertical meridian and steepening in the horizontal meridian which accounts for ATR astigmatic change.

The pattern of induced astigmatism continues to be almost uniform during all the follow up visits i.e. the surgical shift in axis continues to remain by and large unaltered especially the unconventional shifts with the conventional shifts in some patients returning gradually to neutral axes resulting in astigmatic neutrality. The WTR shift in ECCE continues to decrease as the sutures get slowly absorbed and the surgical scar tends to relax causing a mild slowly progressive flattening along the vertical meridian so as to restore the preoperative curvature. In the SICS group the ATR shift also decreases gradually as the wound lips start apposing and the wound gap tends to scar and contracts resulting in mild progressive steepening along the vertical meridian in an attempt to attain the preoperative curvature.

These progressive contour changes continue to progress over years after the operation, the evaluation and analysis of which is beyond the scope of this study.

\section{Conclusion}

It is concluded that SICS induces less surgically induced astigmatism, less inflammation, less complications influencing the overall visual prognosis and quick stabilization of refraction, hence providing better and rapid visual rehabilitation in the postoperative period. The quest for "No Glasses" at the 
end of operation is becoming more of a reality without the need of phacoemulsification which is still a dream for majority of the patients in a developing country like India having enormous surgical load but without an adequate financial support.

\section{Funding: Nil}

Conflict of interest: Nil

Permission from Institutional Research Board (IRB): Yes

\section{References}

1. Brian G, Taylor H. Cataract blindness challenges for the 21st century. Bull World Health Organ 2001; 79:249-56.

2. Venkatesh R, Das M, Prashanth S, Muralikrishnan R. Manual small incision cataract surgery in eyes with white cataracts. Indian J Ophthalmol. 2005; 53(3):173-6

3. Gogate PM, Deshpande M, Wormald RP. Is manual small incision cataract surgery affordable in the developing countries? A cost comparison with extracapsular cataract extraction. Br J Ophthalmol. 2003 Jul; 87 (7):843-6.

4. Kelman CD. Phacoemulsification and aspiration: a new technique of cataract removal: a preliminary report. Am J Ophthalmol. 1967 Jul;64(1):23-35.

5. Colvard DM, Kratz RP, Mazzocco TR, Davidson B. Clinical evaluation of the Terry surgical keratometer. J Am Intraocul Implant Soc. 1980 Jul;6(3):249-51.

6. Girard LJ, Hoffman RF. Scleral tunnel to prevent induced astigmatism. Am J Ophthalmol. 1984 Apr;97(4):450-6.
7. Blumenthal M, Ashkenazi I, Assia E, Cahane M. Small incision manual extracapsular cataract extraction using selective hydrodissection. Ophthalmic Surg. 1992 Oct;23(10):699-701.

8. Myron Yanoff, Jay S. Duker. Data collection and analysis. Ophthalmology. Myron yanoff 1999; 4.33;2.

9. Ravi Thomas, Aby Jacob, Thomas George. Small incision cataract surgery. Recent advances in Ophthalmology, HV Nema 1996; 3: 57-74.

10. Burgansky Z, Isakov I, Avizemer H, Bartov E. Minimal astigmatism after sutureless planned extracapsular cataract extraction. J Cataract Refract Surg. 2002 Mar;28(3):499-503.

11. Kimura H, Kuroda S, Mizoguchi N, Terauchi H, Matsumura M, Nagata M. Extra-capsular cataract extraction with a sutureless incision for dense cataracts. J Cataract Refract Surg. 1999 Sep;25(9):1275-9.

12. Richard L. Lindstrom. Control of Astigmatism in the cataract patient. Cataract surgery- technique, complications and management. Steinert 1995; 232.

13. Oshika T, Sugita G, Tanabe T, Tomidokoro A, Amano S. Regular and irregular astigmatism after superior versus temporal scleral incision cataract surgery. Ophthalmology 2000 Nov;107 (11):2049-53.

14. Ernest PH, Lavery KT, Kiessling LA. Relative strength of scleral tunnel incisions with internal corneal lips constructed in cadaver eyes. J Cataract Refract Surg. 1993 Jul;19(4):457-61.

15. KPS Malik, Ruchi Goel. Manual small incision cataract surgery. All India ophthalmological society CME; 8: 1-31.

\section{How to cite this article?}

Khanday S, Wani RM, Ramzan R, Runyal F. A comparative study of astigmatism following manual small incision cataract surgery and conventional extracapsular cataract extraction at a tertiary centre in Northern India. Int $J$ Med Res Rev 2015;3(5):507-513. doi: 10.17511/ijmrr.2015.i5.098. 